\title{
Gene- gene interaction between PPARG and CYP1A1 gene on coronary artery disease in the Chinese Han population
}

\author{
Xiaojiang Zhang ${ }^{1, *}$, Shuzheng Lv ${ }^{1}$, Chengjun Guo ${ }^{1}$, Conghong Shi ${ }^{2,}{ }^{*}$, Yunpeng Chi ${ }^{1}$, Lin \\ Zhao', Guozhong Wang ${ }^{1}$, Zhisheng Wang ${ }^{1}$ \\ ${ }^{1}$ Department of Cardiology, Beijing Anzhen Hospital, Capital University of Medical Sciences, Beijing 100029, China \\ ${ }^{2}$ Baotou Fourth Hospital, Baotou, Inner Mongolia, 014030, China \\ *These authors contributed equally to this work
}

Correspondence to: Shuzheng Lv, email: Ivsszz552@163.com

Keywords: PPARG, CYP1A1, coronary artery disease, SNP, interaction

Received: February 17, 2017 Accepted: March 06, 2017 Published: March 14, 2017

Copyright: Zhang et al. This is an open-access article distributed under the terms of the Creative Commons Attribution License (CC-BY), which permits unrestricted use, distribution, and reproduction in any medium, provided the original author and source are credited.

\section{ABSTRACT}

Aims: To observe the influence of the peroxisome proliferator-activator receptor-G (PPAR-G) gene and cytochrome P4501A1 (CYP1A1) single-nucleotide polymorphisms (SNPs), and interactions among several SNPs on coronary artery disease (CAD) risk.

Methods: A total of 1106 participants (including 583 males and 523 females) including 550 CAD patients and 556 control subjects were recruited in this study, and the mean age for these participants was $55.5 \pm 11.8$ years old. Logistic regression was used to observe association of SNP within PPARG and CYP1A1 with CAD risk and GMDR model was used to screen the best interaction combinations.

Results: CAD susceptibility was higher in those with homozygous mutant of rs10865710, rs1805192 and rs4646903 than those with wild-type homozygotes, OR $(95 \% \mathrm{CI})$ were $1.47(1.15-1.92), 1.69$ (1.27-2.09) and $1.72(1.35-2.32)$, respectively. We also found a significant two-locus model involving rs1805192 and rs4646903 $(p=0.0107)$, and the cross-validation consistency of this locus model was 10 of 10, the testing accuracy of this model is $62.17 \%$. Logistic regression shown that CAD risk was the highest in those with rs1805192- Pro/Ala or Ala/Ala and rs4646903- AG+GG genotype, and was lowest in those with rs1805192- Pro/ Pro and rs4646903- AA genotype, $\mathrm{OR}(95 \% \mathrm{CI})=3.56(1.91-5.42)$.

Conclusions: Polymorphism in rs10865710, rs1805192 and rs4646903 and interaction between rs1805192 and rs4646903 were related with increased CAD susceptibility.

\section{INTRODUCTION}

Coronary artery disease (CAD), which was an important chronic disease cause of death worldwide [1], has accounts to almost $40 \%$ of all mortalities in many countries $[2,3]$. CAD is influenced by multifactorial factors and may result from the complex synergistic reaction between genetic background and environmental factors [4]. Previously several CAD related variants and environmental factors were reported, such as type 2 diabetes mellitus (T2DM), dyslipidemia, hypertension and genetic factors, including proliferator-activator receptor- $\mathrm{G}$ $(P P A R-G)$ and Cytochrome P450 (CYP) family, are significant risk factors for CAD [5-7].
The PPARG gene, located at $3 \mathrm{p} 25-24$, and plays a non-ignorable role in adipocytes differentiation, insulin sensitivity regulation, and its variation has been reported association with some CAD related risk factors, such as T2DM or metabolic syndrome (MS) [8]. Additionally, $P P A R G$ also play important role in regulation for fatty acid metabolism, perhaps in adipose tissue storage and free fatty acids reduction. Many studies have been conducted to investigate the association of PPARG polymorphism with CAD susceptibility, but the results obtained from these studies were controversial [9-11]. CYP is a kind of enzymes, which could mediate the oxidative metabolism of exogenous and endogenous molecules [12], and metabolism for several endogenous 
molecules, such as cholesterol, estrogens, androgens, and so on $[13,14]$. Recently, several studies have reported the association between $C Y P 1 A 1$ polymorphisms and the risk of CAD susceptibility [15-17]. As fore- mentioned that $\mathrm{CAD}$ risk was influenced by many gene polymorphisms or interactions among several genes, considering CYP1A1 and $P P A R G$ both are risk factor of CAD, however, to date, less study focused on PPAR G-CYPIA1 interaction on CAD risk was reported, so the aim of this study was to investigate the impact of PPARG and CYP1A1 polymorphisms, and synergistic interaction between the two genes on CAD risk.

\section{RESULTS}

In this study, 1106 participants (583 men, 523 women) including $550 \mathrm{CAD}$ cases and 556 control subjects were recruited, and the mean of age for these participants is $55.5 \pm 11.8$ years old. Table 1 shows the clinical characteristics for the participants in cases and controls. The means of BMI and WC are higher in CAD case group than that in control group. There are no significant different between cases and controls in distribution of males, rate of high- fat and low fiber diet, alcohol drinking and smoking and mean of age.

Table 2 shows the frequencies of alleles and genotypes within four SNPs in cases and controls. We found that the variants in rs10865710, rs1805192 and rs4646903 were related with increased CAD risk after covariant adjustment. CAD risks were higher in carriers of homozygous mutant of rs10865710, rs1805192 and rs4646903, and lower in those with wild-type homozygotes, OR $(95 \% \mathrm{CI})$ were 1.47 (1.15-1.92), 1.69 (1.27-2.09) and 1.72 (1.35-2.32), respectively.

GMDR model was used to screen the potential best interaction combination among SNPs within PPARG and CYP1A1. In Table 3, we found that there was a significant gene-gene interaction between rs1805192 and rs4646903. In this model, the cross-validation consistency is $10 / 10$ and the testing accuracy is $62.17 \%$. Logistic regression indicated that participants with rs1805192- Pro/Ala or Ala /Ala and rs4646903- TC+CC genotype have the highest CAD risk, compared to participants with rs1805192- Pro/ Pro and rs4646903- TT genotype, OR (95\%CI) was 3.56 (1.91-5.42), after covariant adjustment (Table 4).

Pairwise LD analysis between SNPs was performed and the $\mathrm{D}^{\prime}$ value between rs10865710 and rs 1805192 was 0.835 , and the $\mathrm{D}^{\prime}$ value between rs4646903 and rs1048943 was 0.808 . So we also conducted haplotype analysis between rs 10865710 and rs 10865710 , between rs4646903 and rs1048943. We found a haplotype containing the rs10865710-G and rs1805192-A alleles within PPARG were associated with a statistically increased CAD risk, OR $(95 \% \mathrm{CI})=2.08(1.47-2.72), P<0.001$, however we did not find any haplotype combination within CYP1A1 associated with CAD risk (Table 5).

\section{DISCUSSION}

In current study based on Chinese Han population, we found that variants in rs10865710, rs1805192 and rs4646903 were associated with higher CAD risk. The $P P A R G$ gene plays an important role in adipocytes differentiation, insulin sensitivity regulation, and its variation has been reported association with some CAD related risk factors, such as T2DM or metabolic syndrome (MS) [8]. Additionally, PPARG also play important role in regulation for fatty acid metabolism, perhaps in adipose tissue storage and circulating concentrations of free fatty acids reduction. Many studies have been conducted to investigate the association between $P P A R G$ polymorphism and CAD risk, but the results obtained from these studies were controversial [9-11]. Rhee et al. [9] suggested that rs1805192 polymorphism in exon B of PPARG was not associated with prevalence of CAD in Korean adults, the similar results were also found in Caucasians [18] and in Indian Population [19]. In a Chinese study, Zhou et al. [10] also reported no association was obtained between and HDL cholesterol in CAD patients. In gender difference analysis, the rate for the $\mathrm{T}$ allele is significantly lower in males, subjects with age less than 62 years, and nonsmokers. But Liu et al. [20] suggested that both rs 1805192 and rs10865710 polymorphisms were associated with CVD related risk factors, but was not associated with lipid and nutrition metabolism. Wu et al. [21] performed a meta- analysis and indicated that the Ala allele in rs1805192 might related to increased CAD risk, but this effect is stronger in Caucasians and barely in Asians.

CYP is a kind of enzymes, which could mediate the oxidative metabolism of exogenous and endogenous molecules [12], could also play an important role in metabolism for several endogenous molecules, such as cholesterol, estrogens, androgens, and so on [13, 14]. Recently, several studies have reported the association between CYP1A1 polymorphisms and the risk of CAD susceptibility [15-17]. Manfredi et al. [22] found that CYP1A1 polymorphisms did not influence CAD susceptibility. Taspinar et al. [23] also suggested that CYP1A1 genotypes were not significantly different between patients and controls. A meta- analysis [24] suggested that the CYP1A1 rs4646903 polymorphism was not correlated with CAD risk. Yeh et al. [25] suggested that CYP1A1 polymorphism may be associated with the lower susceptibility to CAD, particularly in non-smokers. However, some studies concluded different results. Sultana et al. [26] suggested that ischemic stroke (IS) risk was higher in subjects with CYP1A1- CC genotype. Wang et al. [15] reported that $C Y P 1 A 1 \mathrm{MspI}$ polymorphisms are associated with increased CAD risk. Zou et al. [17] conducted a casecontrol study for Chinese Uygur and Han and they indicated that both rs12441817 and rs4886605 within CYP1A1 gene are correlated with CAD susceptibility. 
Table 1: General characteristics of study participants in CAD cases and controls

\begin{tabular}{lccc}
\hline Variables & CAD cases $(\boldsymbol{n}=\mathbf{5 5 0})$ & Controls $(\boldsymbol{n}=\mathbf{5 5 6})$ & $\boldsymbol{p}$-values \\
\hline Age (years) & $57.1 \pm 12.8$ & $56.9 \pm 13.0$ & 0.780 \\
Males N (\%) & $287(52.2)$ & $296(53.2)$ & 0.725 \\
Drinking N (\%) & $231(42.0)$ & $212(38.1)$ & 0.189 \\
Smoke N (\%) & $202(36.7)$ & $190(34.2)$ & 0.374 \\
WC $(\mathrm{cm})$ & $85.1 \pm 14.1$ & $82.3 \pm 15.3$ & 0.002 \\
BMI $\left(\mathrm{kg} / \mathrm{m}^{2}\right)$ & $24.7 \pm 9.8$ & $23.4 \pm 9.5$ & 0.025 \\
High fat diet N (\%) & $120(21.8)$ & $105(18.9)$ & 0.226 \\
Low fiber diet N (\%) & $138(25.1)$ & $116(20.9)$ & 0.095 \\
\hline
\end{tabular}

Abbreviations: WC, waist circumference; BMI, body mass index

Table 2: Analysis on the association between 4 SNPs and CAD risk

\begin{tabular}{|c|c|c|c|c|c|c|}
\hline \multirow{2}{*}{ SNPs } & \multirow{2}{*}{ Genotypes and Alleles } & \multicolumn{2}{|c|}{ Frequencies N (\%) } & \multirow{2}{*}{ OR(95\%CI)* } & \multirow{2}{*}{$P$-values } & \multirow{2}{*}{ H-W test } \\
\hline & & Cases $(n=550)$ & $\operatorname{Controls}(n=556)$ & & & \\
\hline \multicolumn{7}{|c|}{ PPAR G } \\
\hline \multicolumn{7}{|c|}{ rs 10865710} \\
\hline & $\mathrm{CC}$ & $287(52.2)$ & $335(60.3)$ & 1.00 & & 0.351 \\
\hline & $\mathrm{CG}$ & $223(40.5)$ & $198(35.6)$ & $1.22(1.06-1.47)$ & 0.018 & \\
\hline & GG & $40(7.3)$ & $23(4.1)$ & $1.86(1.42-2.34)$ & $<0.001$ & \\
\hline & $\mathrm{GG}+\mathrm{CG}$ & $263(47.8)$ & $221(39.7)$ & $1.47(1.15-1.92)$ & $<0.001$ & \\
\hline & $\mathrm{C}$ & $797(72.5)$ & $868(78.1)$ & & & \\
\hline & G & $303(27.5)$ & $244(21.9)$ & & & \\
\hline \multicolumn{7}{|c|}{ rs1805192 } \\
\hline & Pro/Pro & $283(51.4)$ & $340(61.2)$ & 1.00 & & 0.620 \\
\hline & Pro/Ala & $211(38.4)$ & $187(33.6)$ & $1.43(1.12-1.78)$ & $<0.001$ & \\
\hline & Ala/Ala & $56(10.2)$ & $29(5.2)$ & $2.15(1.56-2.86)$ & $<0.001$ & \\
\hline & $\mathrm{Ala} / \mathrm{Ala}+\mathrm{Pro} / \mathrm{Ala}$ & $267(48.6)$ & $216(38.8)$ & $1.69(1.27-2.09)$ & $<0.001$ & \\
\hline & Pro & $777(70.6)$ & $867(78.0)$ & & & \\
\hline & Ala & $323(29.4)$ & $245(22.0)$ & & & \\
\hline \multicolumn{7}{|c|}{$\begin{array}{c}\text { CYP1A1 } \\
\text { rs4646903 }\end{array}$} \\
\hline & TT & $270(49.1)$ & $350(63.0)$ & 1.00 & & 0.880 \\
\hline & $\mathrm{TC}$ & $219(39.8)$ & $183(32.9)$ & $1.52(1.24-1.97)$ & $<0.001$ & \\
\hline & $\mathrm{CC}$ & $61(11.1)$ & $23(4.1)$ & $2.08(1.44-2.72)$ & $<0.001$ & \\
\hline & $\mathrm{TC}+\mathrm{CC}$ & $280(50.9)$ & $206(37.0)$ & $1.72(1.35-2.32)$ & $<0.001$ & \\
\hline & $\mathrm{T}$ & $759(69.0)$ & $883(79.4)$ & & & \\
\hline & $\mathrm{C}$ & $341(31.0)$ & $229(20.6)$ & & & \\
\hline \multicolumn{7}{|c|}{ rs 1048943} \\
\hline & $\mathrm{AA}$ & $310(56.4)$ & $337(60.6)$ & 1.00 & & 0.889 \\
\hline & $\mathrm{AG}$ & $199(36.2)$ & $191(34.4)$ & $1.12(0.94-1.47)$ & 0.428 & \\
\hline & GG & $41(7.4)$ & $28(5.0)$ & $1.38(0.90-1.95)$ & 0.625 & \\
\hline & $\mathrm{GG}+\mathrm{AG}$ & $240(43.6)$ & $219(39.4)$ & $1.18(0.93-1.62)$ & 0.516 & \\
\hline & A & $819(74.5)$ & $865(77.8)$ & & & \\
\hline & G & $281(25.5)$ & $247(22.2)$ & & & \\
\hline
\end{tabular}

${ }^{a}$ Adjustment for gender, age, alcohol consumption, high fat diet, low fiber diet, BMI and WC.

CAD susceptibility is influenced by many gene polymorphisms and gene- gene interactions, considering $C Y P 1 A 1$ and $P P A R G$ both are risk factor of CAD, however, till now, no study focused on PPARG-CYP1A1 interaction on CAD risk was reported. In this study, we found that interaction between rs1805192 and rs4646903 was also correlated with CAD risk, and the CAD risk was highest in participants with rs1805192- Pro/ Ala or Ala/ Ala and 
Table 3: Best gene-gene interaction models, as identified by GMDR

\begin{tabular}{|c|c|c|c|c|}
\hline Locus no. & Best combination & $\begin{array}{c}\text { Cross-validation } \\
\text { consistency }\end{array}$ & $\begin{array}{c}\text { Testing } \\
\text { accuracy }\end{array}$ & $p$-values ${ }^{a}$ \\
\hline 2 & rs1805192 rs4646903 & $10 / 10$ & 0.6217 & 0.0010 \\
\hline 3 & rs1805192 rs4646903 rs10865710 & $8 / 10$ & 0.5399 & 0.0547 \\
\hline 4 & rs1805192 rs4646903 rs10865710 rs1048943 & $7 / 10$ & 0.4958 & 0.1719 \\
\hline
\end{tabular}

${ }^{a}$ Adjustment for gender, age, alcohol consumption, high fat diet, low fiber diet, BMI and WC.

Table 4: Interaction between rs1805192 and rs4646903 on CAD risk

\begin{tabular}{cccc}
\hline rs1805192 & rs4646903 & OR $(\mathbf{9 5 \%} \mathbf{C I})^{\text {a }}$ & $\boldsymbol{P}$-values \\
\hline PP & TT & 1.00 & - \\
PP & TC + CC & $1.56(1.19-2.04)$ & 0.001 \\
PA or AA & TT & $1.37(1.06-1.83)$ & 0.032 \\
PA or AA & TC + CC & $3.56(1.91-5.42)$ & $<0.001$ \\
\hline
\end{tabular}

a Adjustment for gender, age, alcohol consumption, high fat diet, low fiber diet, BMI and WC.

Abbreviations: P: Pro, A: Ala

Table 5: Haplotype analysis on association of $P P A R G$ and $C Y P 1 A 1$ gene and CAD risk

\begin{tabular}{|c|c|c|c|c|c|c|}
\hline \multirow{2}{*}{ Haplotypes } & \multirow{2}{*}{ SNP1 } & \multirow{2}{*}{ SNP2 } & \multicolumn{2}{|c|}{ Frequencies } & \multirow{2}{*}{ OR $(95 \% \mathrm{CI})$} & \multirow{2}{*}{$p$-values* } \\
\hline & & & Case group & Control group & & \\
\hline$P P A R G$ & rs 10865710 & rs1805192 & & & & \\
\hline H1 & C & $\mathrm{P}$ & 0.4701 & 0.5467 & 1.00 & -- \\
\hline $\mathrm{H} 2$ & G & $\mathrm{P}$ & 0.2167 & 0.2131 & $1.16(0.82-1.69)$ & 0.670 \\
\hline $\mathrm{H} 3$ & $\mathrm{C}$ & A & 0.2015 & 0.1971 & $1.29(0.93-1.78)$ & 0.412 \\
\hline $\mathrm{H} 4$ & G & $\mathrm{A}$ & 0.1117 & 0.0431 & $2.08(1.47-2.72)$ & $<0.001$ \\
\hline CYP1A1 & rs4646903 & rs1048943 & & & & \\
\hline H1 & $\mathrm{T}$ & A & 0.5322 & 0.5431 & 1.00 & -- \\
\hline $\mathrm{H} 2$ & $\mathrm{C}$ & A & 0.2064 & 0.2101 & $1.06(0.72-1.48)$ & 0.562 \\
\hline H3 & $\mathrm{T}$ & G & 0.1897 & 0.1947 & $0.98(0.67-1.43)$ & 0.635 \\
\hline $\mathrm{H} 4$ & $\mathrm{C}$ & $\mathrm{G}$ & 0.0717 & 0.0521 & $1.23(0.77-1.81)$ & 0.724 \\
\hline
\end{tabular}

*Adjusted for gender, age, smoking and BMI

rs4646903- TC+CC genotype, and was lowest in participants with rs1805192- Pro/ Pro and rs4646903- TT genotype. The potential mechanism for this interaction was not very clearly, some studies have reported that both PPARG and CYPIAI gene polymorphisms were associated with CAD related- risk factors, such as T2DM, obesity and hypertension, and so on. Maybe this combined or crossover effect could lead to the interaction between PPARG and CYPIA1 gene on CAD risk.

There are several limitations in our study. Firstly, more SNPs within PPARG or CYP1A1 gene should been studied in the future study, particularly some less studied SNPs. Secondly, some environmental risk factors should be included to investigate gene- environment interaction, such as smoking or alcohol drinking and so on.

In conclusion, we found that variants in rs10865710, rs1805192 and rs4646903 were significantly related with increased CAD risk. We also found a significant interaction between rs1805192 and rs4646903, and CAD risk was highest in participants with rs1805192- Pro/ Ala or Ala/ Ala and rs4646903- TC+CC genotype, and was lowest in those with rs1805192- Pro/ Pro and rs4646903TT genotype.

\section{MATERIALS AND METHODS}

\section{Subjects}

All participants were recruited from 6 June 2012 to 15 November 2014 from Beijing Anzhen Hospital. The CAD patients were diagnosed by coronary angiography using a quantitative coronary angiographic system [27]. The control subjects were randomly recruited from another 
population investigation program for chronic disease and related risk factors in our city and with nearly 1:1 matched to cases group on the basis of age ( \pm 3 years) and gender. Participants with hypertension, type 2 diabetes (T2DM), and others CAD related risks were excluded from the control group (Figure 1). Writing informed consents were signed by all participants.

\section{Information collection}

We collected related information by using questionnaire and body measurement. In the questionnaire investigation, some information, such as demographic information, alcohol drinking, tobacco smoke and diet habit information for all cases and controls were collected. In the body measurement procedure, some parameters, such as waist circumference (WC), body weight and height were measured, and then BMI was calculated. Currently alcohol drinkers were defined as those who drink more than 1 times every month; those who have smoked for at least 100 cigarettes and still smoked at the time of the investigation were considered as current smokers. Blood samples of all participants were all collected during the investigation.

\section{Genomic DNA extraction and genotyping}

We selected SNPs within the PPARG and CYP1A1 gene according to the following methods, including: 1) which have been reported associations with $\mathrm{CAD}$ or risk factors of CAD; 2) minor allele frequency (MAF) greater than $5 \%$. Taking into account the limitations of human, material and financial resources, a total of two SNPs in PPARG and two SNPs in CYP1A1 were selected for genotyping in the study: rs1805192, rs4646903, rs10865710 and rs1048943. Genomic DNA of all participants was extracted from the collected EDTA-treated whole blood by using the DNA Blood Mini Kit (Qiagen, Hilden, Germany) according to the instruction manual. The genotyping for all SNPs were performed by using Taqman fluorescence probe. Table 6 shows the corresponding probe sequences and description for all SNPs. ABI Prism7000 software was used for genotyping. A $25 \mu$ reaction mixture including $1.25 \mathrm{ul}$ SNP Genotyping Assays (20×), $12.5 \mu$ l Genotyping Master Mix (2×), $20 \mathrm{ng}$ DNA, and the conditions were as follows: initial denaturation for $9 \mathrm{~min}$ and $94^{\circ} \mathrm{C}$, denaturation for $18 \mathrm{~s}$ and $93^{\circ} \mathrm{C}$, annealing and extension for $80 \mathrm{~s}$ and $62^{\circ} \mathrm{C}$, 50 cycles.

\section{Statistical analysis}

The means and standard deviations (SDs) were calculated for normally distributed continuous variables and were compared between cases and controls using Student's $t$ test, and percentages are also calculated for categorical variables and are compared between case group and control group by using $\chi^{2}$ test. The association between SNPs and CAD and Hardy-Weinberg equilibrium (HWE) were performed by using SNPStats. Logistic regression was used to observe association of SNP within PPARG and CYP1A1 with CAD risk. Generalized multifactor dimensionality reduction (GMDR) model was used to analyze the gene- gene interaction, some parameters including cross-validation consistency,

Participants were consecutively recruited between 6 June 2012 and 15 November 2014 from Beijing Anzhen Hospital

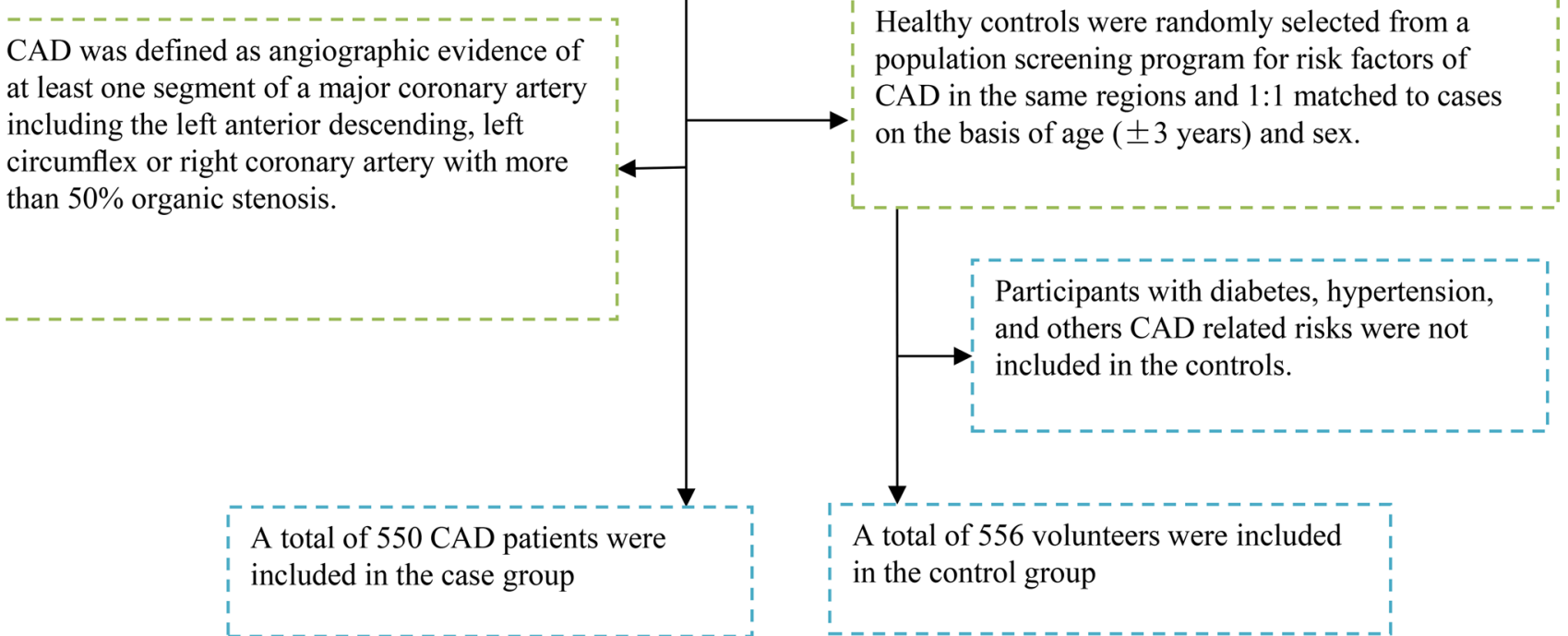

Figure 1: A flowchart on study population selection and exclusion. 
Table 6: Description and Probe sequence used for Taqman fluorescence probe analysis for 4 SNPs

\begin{tabular}{|c|c|c|c|c|c|}
\hline ID & SNP & Chromosome & $\begin{array}{c}\text { Functional } \\
\text { Consequence }\end{array}$ & $\begin{array}{l}\text { Major/minor } \\
\text { allele }\end{array}$ & Probe sequence \\
\hline \multicolumn{6}{|l|}{ PPARG } \\
\hline rs 10865710 & $C 681 G$ & 3 & Exon_A2 & $\mathrm{C} / \mathrm{G}$ & $\begin{array}{l}\text { 5'-TTGGCATTAGATGCTGTTTTGTCTT[C/G] } \\
\text { ATGGAAAATACAGCTATTCTAGGAT-3' }\end{array}$ \\
\hline rs 1805192 & Pro12Ala & 3 & Exon_B & $\mathrm{C} / \mathrm{G}$ & $\begin{array}{l}\text { 5'-ACCTCAGACAGATTGTCACGGAACA[C/T] } \\
\text { GTGCAGCTACTGCAGGTGATCAAGA-3' }\end{array}$ \\
\hline \multicolumn{6}{|l|}{ CYP1A1 } \\
\hline rs 1048943 & $A 4889 G$ & 15 & Missense & $\mathrm{A} / \mathrm{G}$ & $\begin{array}{l}\text { 5'-CAAGCGGAAGTGTATCGGTGAGACC[A/G] } \\
\text { TTGCCCGCTGGGAGGTCTTTCTCTT-3' }\end{array}$ \\
\hline rs4646903 & T6235C & 15 & $\begin{array}{l}\text { Downstream } \\
\text { variant 500B }\end{array}$ & $\mathrm{T} / \mathrm{C}$ & $\begin{array}{l}\text { 5'- TTGTTTCACTGTAACCTCCACCTCC }[\mathrm{C} / \mathrm{T}] \\
\text { GGGCTCACACGATTCTCCCACCTCA-3' }\end{array}$ \\
\hline
\end{tabular}

the testing balanced accuracy and the sign test were calculated, a sign test or a permutation test (providing empirical $p$-values) for prediction accuracy can be used to measure the significance of an identified model.

\section{ACKNOWLEDGMENTS AND FUNDING}

The writing of this paper was supported by Beijing Anzhen Hospital and Baotou Fourth Hospital. We thank all the staffs who help us in this investigation. Zhang Xiaojiang and Shi Conghong contributed equally to this work.

\section{CONFLICTS OF INTEREST}

None.

\section{REFERENCES}

1. Ezzati M, Hoorn SV, Rodgers A, Lopez AD, Mathers CD, Murray CJ, and Comparative Risk Assessment Collaborating Group. Estimates of global and regional potential health gains from reducing multiple major risk factors. Lancet. 2003; 362:271-80.

2. Aboutabl ME, El-Kadi AO. Constitutive expression and inducibility of CYP1A1 in the $\mathrm{H} 9 \mathrm{c} 2$ rat cardiomyoblast cells. Toxicol In Vitro. 2007; 21:1686-91.

3. Zordoky BN, El-Kadi AO. Effect of cytochrome P450 polymorphism on arachidonic acid metabolism and their impact on cardiovascular diseases. Pharmacol Ther. 2010; $125: 446-63$.

4. Frazier L, Johnson RL, Sparks E. Genomics and cardiovascular disease. J Nurs Scholarsh. 2005; 37:315-21.

5. Winkelmann BR, Hager J. Genetic variation in coronary heart disease and myocardial infarction: methodological overview and clinical evidence. Pharmacogenomics. 2000; 1:73-94.

6. Nordlie MA, Wold LE, Kloner RA. Genetic contributors toward increased risk for ischemic heart disease. J Mol Cell Cardiol. 2005; 39:667-79.
7. Lusis AJ, Mar R, Pajukanta P. Genetics of atherosclerosis. Annu Rev Genomics Hum Genet. 2004; 5:189-218.

8. Savage DB, Tan GD, Acerini CL, Jebb SA, Agostini M, Gurnell M, Williams RL, Umpleby AM, Thomas EL, Bell JD, Dixon AK, Dunne F, Boiani R, et al. Human metabolic syndrome resulting from dominant-negative mutations in the nuclear receptor peroxisome proliferator-activated receptor-gamma. Diabetes. 2003; 52:910-17.

9. Rhee EJ, Kwon CH, Lee WY, Kim SY, Jung CH, Kim BJ, Sung KC, Kim BS, Oh KW, Kang JH, Park SW, Kim SW, Lee MH, Park JR. No association of Pro12Ala polymorphism of PPAR-gamma gene with coronary artery disease in Korean subjects. Circ J. 2007; 71:338-42.

10. Zhou X, Chen J, Xu W. Association between C1431T polymorphism in peroxisome proliferator-activated receptor- $\gamma$ gene and coronary artery disease in Chinese Han population. Mol Biol Rep. 2012; 39:1863-68.

11. Nicholls SJ, Uno K. Peroxisome proliferator-activated receptor (PPAR $\alpha / \gamma$ ) agonists as a potential target to reduce cardiovascular risk in diabetes. Diab Vasc Dis Res. 2012; 9:89-94.

12. Niwa $T$, Murayama $N$, Yamazaki $H$. Oxidation of endobiotics mediated by xenobiotic-metabolizing forms of human cytochrome. Curr Drug Metab. 2009; 10:700-12.

13. Elbekai RH, El-Kadi AO. Cytochrome P450 enzymes: central players in cardiovascular health and disease. Pharmacol Ther. 2006; 112:564-87.

14. Zordoky BN, El-Kadi AO. Modulation of cardiac and hepatic cytochrome P450 enzymes during heart failure. Curr Drug Metab. 2008; 9:122-28.

15. Wang XL, Greco M, Sim AS, Duarte N, Wang J, Wilcken DE. Effect of CYP1A1 MspI polymorphism on cigarette smoking related coronary artery disease and diabetes. Atherosclerosis. 2002; 162:391-97.

16. Cornelis MC, El-Sohemy A, Campos H. Genetic polymorphism of CYP1A2 increases the risk of myocardial infarction. J Med Genet. 2004; 41:758-62.

17. Zou JG, Ma YT, Xie X, Yang YN, Pan S, Adi D, Liu F, Chen BD. The association between CYP1A1 genetic 
polymorphisms and coronary artery disease in the Uygur and Han of China. Lipids Health Dis. 2014; 13:145.

18. Radha V, Vimaleswaran KS, Babu HN, Abate N, Chandalia M, Satija P, Grundy SM, Ghosh S, Majumder PP, Deepa R, Rao SM, Mohan V. Role of genetic polymorphism peroxisome proliferator-activated receptor-2 Pro12Ala on ethnic susceptibility to diabetes in South-Asian and Caucasian subjects. Diabetes Care. 2006; 29:1046-51.

19. AshokKumar M, Veera Subhashini NG, Kanthimathi S, SaiBabu R, Ramesh A, Cherian KM, Emmanuel C. Associations for lipoprotein lipase and peroxisome proliferator-activated receptor-gamma gene and coronary artery disease in an Indian population. Arch Med Res. 2010; 41:19-25.e1.

20. Liu F, Mei X, Zhang Y, Qi H, Wang J, Wang Y, Jiang W, Zhang X, Yan H, Zhuang S. Association of peroxisome proliferator-activated receptor $\gamma$ gene Pro12Ala and C161T polymorphisms with cardiovascular risk factors in maintenance hemodialysis patients. Mol Biol Rep. 2014; 41:7555-65.

21. Wu Z, Lou Y, Jin W, Liu Y, Lu L, Lu G. The Pro12Ala polymorphism in the peroxisome proliferator-activated receptor gamma-2 gene (PPAR $\gamma 2)$ is associated with increased risk of coronary artery disease: a meta-analysis. PLoS One. 2012; 7:e53105.

22. Manfredi S, Federici C, Picano E, Botto N, Rizza A, Andreassi MG. GSTM1, GSTT1 and CYP1A1 detoxification gene polymorphisms and susceptibility to smoking-related coronary artery disease: a case-only study. Mutat Res. 2007; 621:106-12.

23. Taspinar M, Aydos S, Sakiragaoglu O, Duzen IV, Yalcinkaya A, Oztuna D, Bardakci H, Tutar E, Sunguroglu A. Impact of genetic variations of the CYP1A1, GSTT1, and GSTM1 genes on the risk of coronary artery disease. DNA Cell Biol. 2012; 31:211-18.

24. Zhang J, Wang Y, Liu Y, Zhang X. Lack of association between CYP1A1 T6235C polymorphism and coronary artery disease: evidence from a meta-analysis. Mol Med Rep. 2013; 7:543-48.

25. Yeh CC, Sung FC, Kuo LT, Hsu WP, Chu HY. Polymorphisms of cytochrome P450 1A1, cigarette smoking and risk of coronary artery disease. Mutat Res. 2009; 667:77-81.

26. Sultana S, Kolla VK, Peddireddy V, Jeedigunta Y, Penagaluru PK, Joshi S, Penagaluru UR, Penagaluru PR. Association of CYP1A1 Gene Polymorphism with Ischemic Stroke in South Indian Population. Transl Stroke Res. 2011; 2:26-32.

27. Santamore WP, Kahl FR, Kutcher MA, Negin M, Whiteman JL, Kase JP, Little WC. A microcomputer based automated, quantitative coronary angiographic analysis system. Ann Biomed Eng. 1988; 16:367-77. 